\title{
Financial Hardship from Purchasing Medications for Senior Citizens Before and After the Medicare Modernization Act of 2003 and the Patient Protection and Affordable Care Act of 2010: Findings from 1998, 2001, and 2015
}

\author{
Anthony W. Olson, PharmD; Jon C. Schommer, PhD; David A. Mott, PhD; and Lawrence M. Brown, PhD
}

\begin{abstract}
BACKGROUND: The Medicare Modernization Act of 2003 (Medicare Part D) added prescription drug coverage for senior citizens aged 65 years and older and applied managed care approaches to contain costs. The Patient Protection and Affordable Care Act of 2010 (ACA) had the goals of expanding health care insurance coverage and slowing growth in health care expenditures.
\end{abstract}

OBJECTIVES: To (a) describe the proportion of senior citizens who had prescription drug insurance coverage and the proportion who experienced financial hardship from purchasing medications in 2015, and (b) compare the findings with those collected in 1998 and 2001.

METHODS: Data were obtained in 1998 and 2001 via surveys mailed to national random samples of seniors. Of 2,434 deliverable surveys, 946 (39\%) were returned, and $700(29 \%)$ provided usable data. Data were collected in 2015 via an online survey sent to a national sample of adults. Of 26,173 usable responses, 3,933 were aged 65 years or older. Descriptive statistics and logistic regression analyses described relationships among study variables.

RESULTS: Results showed that the proportion of seniors without prescription coverage was $9 \%$ in 2015 , a decrease from $29 \%$ in 2001 and $32 \%$ in 1998. The proportion of senior citizens reporting financial hardship from medication purchases was $36 \%$ in 2015 , a rise from $31 \%$ in 2001 and $19 \%$ in 1998. For those without prescription drug coverage, $34 \%, 55 \%$, and $49 \%$ reported financial hardship in 1998, 2001, and 2015, respectively. For those with drug coverage, $12 \%, 22 \%$, and $35 \%$ reported financial hardship in 1998, 2001, and 2015, respectively.

CONCLUSIONS: After implementation of Medicare Part D and the ACA, the proportion of seniors without prescription drug coverage decreased. However, self-reported financial hardship from purchasing medications increased. Senior citizens with prescription drug insurance may be experiencing financial hardship from increasing out-of-pocket costs for insurance premiums, cost sharing, and full-cost obligation for some medications.

J Manag Care Spec Pharm. 2016;22(10):1150-58

Copyright $\odot 2016$, Academy of Managed Care Pharmacy. All rights reserved.

\section{What is already known about this subject}

Insurance coverage for prescriptions influences patient medication use and its associated expenditures.

People without prescription drug coverage face greater financial burdens and medication adherence issues than those with drug coverage.

The use of cost-sharing methods such as copayments and coinsurance for prescription coverage rose significantly in the years before the passage of Medicare Part D.

\section{What this study adds}

Study analysis showed that the proportion of seniors with prescription drug insurance coverage increased between 2001 and 2015, but seniors who experienced financial hardship from purchasing medications also increased during this time period. The association of prescription drug insurance coverage and financial hardship from prescription medication purchases may be affected by out-of-pocket costs incurred through cost-sharing mechanisms.

$\mathrm{B}$ efore the passage of the Medicare Modernization Act of 2003, researchers described the financial burden of prescription drug costs for senior citizens (individuals aged 65 years and older ${ }^{1-7}$ and examined the association between prescription drug insurance coverage and patterns of drug use and associated drug expenditures. ${ }^{6-8}$ The findings showed that insurance coverage for prescription drugs influenced the amount of drugs people obtained, how much they spent on drugs out-of-pocket, and how much was spent in total on their behalf. People with coverage not only obtained more prescription medications than those without coverage, but also were likely to have access to a broader array of therapies, including more costly therapies. People without prescription drug coverage faced greater financial burdens and sometimes were unable to follow the courses of treatment prescribed by their physicians. ${ }^{6}$ In response to the burden of prescription drug costs, senior citizens used mail order pharmacies, prescription 
drug discount cards, and less expensive prescription drugs from other countries such as Canada; they also changed their patterns of drug taking to help decrease the costs of the drugs they used..$^{9-14}$

Surveys conducted in 1998 and 2001 of senior citizens living in the United States showed that $68 \%$ reported having prescription drug insurance coverage in 1998 , and $71 \%$ reported having such insurance coverage in $2001 .{ }^{15}$ Although the proportion of senior citizens who had some type of prescription drug coverage did not change significantly from 1998 to 2001, the characteristics of that coverage changed over time. For example, the proportion of respondents who had to share costs of prescriptions through copayments and coinsurance rose significantly between 1998 and 2001. For those with copayments, out-of-pocket amounts increased significantly for brand-name products between 1998 and 2001, as did coinsurance percentages for generic products.

A concern with higher drug costs paid out-of-pocket is the burden that it places on senior citizens. The proportion of seniors who experienced financial burden related to purchasing medications increased from 19\% in 1998 to 31\% in 2001. Lower-income seniors and higher users of prescription drugs were being hit especially hard with the burden of drug costs. ${ }^{15}$ The results from these surveys also showed that insured persons were feeling the burden of drug costs as well, especially high users of prescription drugs. One explanation for the burden among insured persons was the increase in cost sharing experienced by insured persons between 1998 and 2001. 13,15 Regardless of insurance status, drug costs were a financial burden for many seniors, especially for high users of prescription drugs.

To help alleviate the financial burden of purchasing medications for senior citizens, the U.S. Congress passed the Medicare Modernization Act of 2003 (Medicare Part D), which provided Medicare coverage for prescription drugs and used managed care approaches for containing costs associated with prescription drug therapy. This law presented seniors with an assortment of drug coverage plans that varied in structures and benefits. By 2009, there were 45 different plans available in each of the 50 states offering different combinations of premiums, deductibles, coinsurances, tiered copayments, and drug formularies. ${ }^{16}$ Initial standard plans included a $25 \%$ coinsurance up to $\$ 2,250$ in expenditures and a $5 \%$ coinsurance above $\$ 5,100$ in expenditures, with beneficiaries responsible for the full cost of prescription medications between $\$ 2,250$ and $\$ 5,100$ (the donut hole). Since then, other plans have offered tiered copayments as an alternative to coinsurance options, but very few plans have provided any coverage in the donut hole. ${ }^{16}$ A study in 2009 estimated that about 25\% of Medicare Part D beneficiaries surpassed the lower threshold of the donut hole and about 5\% exceeded the upper limit. It found that the increased costs associated with the donut hole lowered prescription drug use. ${ }^{17}$ Other studies showed that decreased drug coverage in Medicare was associated with poorer medication adherence and clinical outcomes along with increased hospitalization costs and emergency room use. ${ }^{18}$

In 2010, the Patient Protection and Affordable Care Act (ACA) was passed with the goals of expanding health care insurance coverage and slowing the growth of health care expenditures. This legislation included provisions for Medicare Part D beneficiaries in the coverage donut hole such as a $\$ 250$ rebate, a 45\%-55\% brand-name medication discount, and an incremental rollout of up to $75 \%$ in federal subsidies for generics by 2020 . The ACA also mandated the elimination of the coverage donut hole by 2020.13,19,20 As of 2015, the Department of Health and Human Services estimated that the ACA had provided 9.4 million seniors with more than $\$ 15$ billion in savings since 2010. ${ }^{21}$

\section{Study Objectives}

In light of provisions provided in Medicare Part D and the ACA, the objectives for this study were to describe the proportion of senior citizens who had prescription drug insurance coverage and the proportion who experienced financial hardship from purchasing medications in 2015 , and to compare the findings with those collected in 1998 and 2001. ${ }^{15}$ In addition, multivariate models were used to assess the association of year $(1998,2001,2015)$; prescription drug insurance coverage (yes, no); and respondent demographics on the proportion of respondents who experienced financial hardship due to purchasing medications.

\section{Methods}

\section{Data Collection}

Data were obtained via mailed survey methodology in 1998 and in 2001 from national random samples of senior citizens. ${ }^{15}$ In 1998, 1,570 individuals aged 65 years and older were selected randomly from the U.S. population. In 2001, 864 individuals aged 65 years and older were selected randomly in the same manner. The sampling frame and mailing addresses were obtained from KM Lists, which compiles a complete listing for the United States from publicly available sources, including telephone directories, drivers license databases, and other public records. KM Lists continually updates its lists and tests them for validity.

Following a modification of Dillman's mailed survey method, ${ }^{22}$ each sampled person was mailed a survey packet 
containing a cover letter requesting his or her participation, the survey form, a postage-paid return envelope, and a $\$ 1$ bill as incentive to participate. A follow-up post card was mailed 1 week after the first mailing to increase response rate. Based on the relatively low response rate that was achieved in 1998 (29\%), a tracking number was added to surveys in order to identify nonresponders in 2001. For those who had not yet responded, a follow-up mailing was sent 3 weeks after the initial mailing to increase response rate. Thus, the 2001 survey used fewer initial sample members but used a more thorough follow-up with nonresponders.

Another addition to the 2001 survey was a question on the cover of the survey in which each recipient of the survey was asked to report the primary reason a person was not able to complete the survey if the sample member was not able to respond. The response categories to this question were (a) person is physically or mentally no longer able to complete the survey, (b) person is now living in a nursing home or other assisted living facility, (c) person is deceased, (d) person is no longer at this address for some other reason, or (e) other. This question allowed us to better understand reasons for nonresponse and the potential for nonresponse bias.

For 2015, data were collected via an online, self-administered survey coordinated by Qualtrics Panels. This survey was designed for a project called The National Consumer Survey on the Medication Experience and Pharmacists' Roles and included questions that allowed the comparison of findings from 2015 with those collected in the 1998 and 2001 surveys. Between April 28, 2015, and June 22, 2015, Qualtrics sent invitations to participate in the survey through its panel partner organizations to the targeted respondents, inviting respondents to complete the online survey in return for incentives/cash honorarium (as established a priori within the panels' agreements). As surveys were being completed, Qualtrics monitored response patterns against established quotas and screening information for this particular study.

On the basis of their monitoring, Qualtrics provided follow-up and made decisions about sampling in order to meet the desired quotas. Of a total of 26,173 responses, 3,933 were from individuals aged 65 years and older and were included in this study.

\section{Study Variables}

Each respondent was asked, "Do you have insurance coverage for prescription drugs?" (yes, no). Also, respondents were asked, "Purchasing medications causes me financial hardship" (categorized as yes, no). This deliberately was a subjective statement that did not explicitly define financial hardship but rather relied on respondents' perceptions about how burdensome the purchase of medications was to them.
For comparison purposes, respondents were asked a series of demographic-related questions. These questions related to the respondents' age, sex, education, marital status, income, race, number of prescription drugs taken daily, number of overthe-counter drugs taken daily, and whether they had arthritis or diabetes (2 relatively common chronic conditions for which there was evidence that they may be associated with other study variables). These demographic variables were included based on a review of the literature that suggested that these variables could influence the other variables in our study.,15

\section{Data Analysis}

Descriptive comparisons were made among respondents in 1998, 2001, and 2015 for demographic, drug payment, and drug procurement variables using analysis of variance and the chi-square test statistic. Then, to control for any differences in the demographic profile of respondents in 1998, 2001, and 2015, a multivariate approach was employed for analysis. Logistic regression analyses were used to test the relationships between the independent variables (year, prescription drug insurance coverage, and respondent demographics) and the dependent variable (financial hardship from purchasing medications). Goodness-of-fit for competing logistic regression models was assessed based on the change in -2 log likelihood and model improvement chi-square (statistically determined goodness-of-fit) and also through parsimony of interpretation (usefulness for application). Descriptive statistics also were computed to help interpret the results.

\section{Results}

In 1998, 463 (29\%) of 1,570 surveys were returned, and in 2001, 483 (56\%) of 864 were returned. Of these 946 responses, 365 contained usable responses in 1998 (plus 98 with no usable responses), and 335 contained usable responses in 2001 (plus 148 with no usable responses). Because of the relatively large number of surveys we received with no usable responses in 1998, we added a question on the cover of the 2001 survey that asked the recipient of the survey to report the primary reason a person was not able to complete the survey if the sample member was not able to respond. A total of 132 of the 148 individuals who were not able to provide usable data provided a reason. Twenty percent reported that the person to whom the survey was addressed was now deceased, 17\% reported that the person was physically or mentally no longer able to complete the survey, $7 \%$ reported that the addressee no longer lived at the address, 5\% reported that the addressee was now living in a nursing home or other assisted living facility, and the remaining 51\% checked "other." Most of those who checked "other" reported that they were not interested in completing 
TABLE 1 Comparisons of Respondent Demographics in 1998, 2001, and 2015

\begin{tabular}{|c|c|c|c|c|}
\hline Characteristic & $\begin{array}{c}1998 \\
(n=365)\end{array}$ & $\begin{array}{c}2001 \\
(n=335)\end{array}$ & $\begin{array}{c}2015^{\mathrm{a}} \\
(\mathrm{n}=3,933) \\
(\mathrm{n}=378) \\
(\mathrm{n}=393) \\
(\mathrm{n}=400)\end{array}$ & $\begin{array}{c}\text { ANOVA or } \\
\text { Chi-square } \\
P \text { Value }\end{array}$ \\
\hline Age, year (mean) & 74.9 & 75.2 & $\begin{array}{l}70.7 \\
70.7 \\
70.6 \\
70.8\end{array}$ & $\begin{array}{l}<0.001 \\
<0.001 \\
<0.001 \\
<0.001\end{array}$ \\
\hline Sex (\% female) & 52 & 45 & $\begin{array}{l}63 \\
62 \\
60 \\
62\end{array}$ & $\begin{array}{l}<0.001 \\
<0.001 \\
<0.001 \\
<0.001\end{array}$ \\
\hline Education (\% with more than a high school education) & 56 & 45 & $\begin{array}{l}76 \\
79 \\
77 \\
76\end{array}$ & $\begin{array}{l}<0.001 \\
<0.001 \\
<0.001 \\
<0.001\end{array}$ \\
\hline Marital status (\% married) & 63 & 59 & $\begin{array}{l}58 \\
61 \\
55 \\
60 \\
\end{array}$ & $\begin{array}{l}0.130 \\
0.490 \\
0.060 \\
0.420\end{array}$ \\
\hline $\begin{array}{l}\text { Income }(\%<\$ 15,000 / \text { year }) \\
\text { For } 2015(\%<\$ 20,000 / \text { year })\end{array}$ & 19 & 25 & $\begin{array}{l}16 \\
15 \\
15 \\
13 \\
\end{array}$ & $\begin{array}{r}<0.001 \\
0.002 \\
0.002 \\
<0.001 \\
\end{array}$ \\
\hline Race (\% white) & 90 & 83 & $\begin{array}{l}91 \\
94 \\
88 \\
94\end{array}$ & $\begin{array}{r}<0.001 \\
<0.001 \\
0.030 \\
<0.001\end{array}$ \\
\hline Number of prescription drugs taken daily (mean) & 2.9 & 3.5 & $\begin{array}{l}4.0 \\
3.9 \\
4.6 \\
3.1 \\
\end{array}$ & $\begin{array}{l}<0.001 \\
<0.001 \\
<0.001 \\
<0.001\end{array}$ \\
\hline Number of OTC drugs taken daily (mean) & 1.0 & 1.7 & $\begin{array}{l}1.5 \\
1.4 \\
1.7 \\
2.2 \\
\end{array}$ & $\begin{array}{l}<0.001 \\
<0.001 \\
<0.001 \\
<0.001\end{array}$ \\
\hline Proportion who have arthritis (\%) & 39 & 46 & $\begin{array}{l}53 \\
52 \\
55 \\
52 \\
\end{array}$ & $\begin{array}{r}<0.001 \\
0.001 \\
<0.001 \\
0.001 \\
\end{array}$ \\
\hline Proportion who have diabetes (\%) & 12 & 16 & $\begin{array}{l}21 \\
20 \\
22 \\
18 \\
\end{array}$ & $\begin{array}{r}<0.001 \\
0.030 \\
0.001 \\
0.140 \\
\end{array}$ \\
\hline
\end{tabular}

aThe smaller sample groups represent analysis of 10\% random samples from the larger sample in 2015.

ANOVA = analysis of variance; OTC $=$ over-the-counter.

surveys or did not think that the survey applied very much to them because they did not take any medications or received their medications through the military.

Initial frequency counts for the data revealed that the income variable exhibited a relatively high number of missing cases: 87 (12\%) of the 700 surveys. To impute values for the missing cases, a logistic regression equation was developed based on the usable data. Then, the equation was used to predict whether a respondent with a missing annual income value should be coded as "less than $\$ 15,000$ " or " $\$ 15,000$ or more." The findings presented in this article include the imputed values. It should be noted that $\$ 15,000$ was representative of poverty thresholds in 1999 and 2001. For 2015, \$20,000 was representative of poverty thresholds.

For the 2015 survey, 26,173 responses were obtained overall. Of these, 3,933 were from individuals aged 65 years and older and were included in this study. Thus, there were 365 usable responses from the 1999 survey, 335 from the 2001 
TABLE 2 Comparisons of Prescription Drug Insurance and Financial Hardship in 1998, 2001, and 2015

\begin{tabular}{|c|c|c|c|c|}
\hline Characteristic & $\begin{array}{c}1998 \\
(\mathrm{n}=365)\end{array}$ & $\begin{array}{c}2001 \\
(\mathrm{n}=335)\end{array}$ & $\begin{array}{c}2015^{a} \\
(n=3,933) \\
(n=378) \\
(n=393) \\
(n=400)\end{array}$ & $\begin{array}{c}\text { Chi-square } \\
P \text { Value }\end{array}$ \\
\hline Have prescription drug insurance (\% yes) & 68 & 71 & $\begin{array}{l}91 \\
91 \\
90 \\
92\end{array}$ & $\begin{array}{l}<0.001 \\
<0.001 \\
<0.001 \\
<0.001\end{array}$ \\
\hline Financial hardship due to Rx drug expenditures (\% yes) & 19 & 31 & $\begin{array}{l}36 \\
36 \\
36 \\
37 \\
\end{array}$ & $\begin{array}{l}<0.001 \\
<0.001 \\
<0.001 \\
<0.001\end{array}$ \\
\hline
\end{tabular}

aThe smaller sample groups represent analysis of 10\% random samples from the larger sample in 2015.

survey, and 3,933 from the 2015 survey. Owing to the 2015 sample being more than 10 times as large as the 1998 and 2001 samples, three 10\%-random-samples from the 2015 data were selected and used as part of the analysis. The sample sizes were 378,393 , and 400 , respectively.

\section{Respondent Demographics}

Table 1 presents comparisons between 1998, 2001, and 2015 for respondent demographics. Most of the variables differed between the survey years. To help control for these differences in the 3 respondent groups (1998, 2001, 2015), multivariate tools were employed for analysis. It should be noted that findings for 2015 using the whole sample and the three 10\%-random-samples were stable and yielded similar results for findings presented in Table 1.

\section{Prescription Drug Insurance}

Table 2 shows that in 2001, compared with 1998, the proportion of senior citizens with prescription insurance coverage did not change significantly ( $71 \%$ vs. $68 \%$, respectively, chi-square $P>0.050$ ). However, there was a significant increase in 2015, with $91 \%$ of respondents reporting prescription drug insurance coverage $(P<0.001)$.

\section{Financial Hardship from Purchasing Medications}

Table 2 also shows that the proportion of respondents who reported financial hardship rose from 19\% in 1998 to 31\% in 2001 and to $36 \%$ in $2015(P<0.001)$. It should be noted that findings using the three $10 \%$-random-samples were stable and yielded similar results.

Figure 1 summarizes the proportion of respondents who reported financial hardship from purchasing medications by year of survey $(1999,2001,2015)$ and by prescription drug insurance coverage status (have prescription drug coverage,
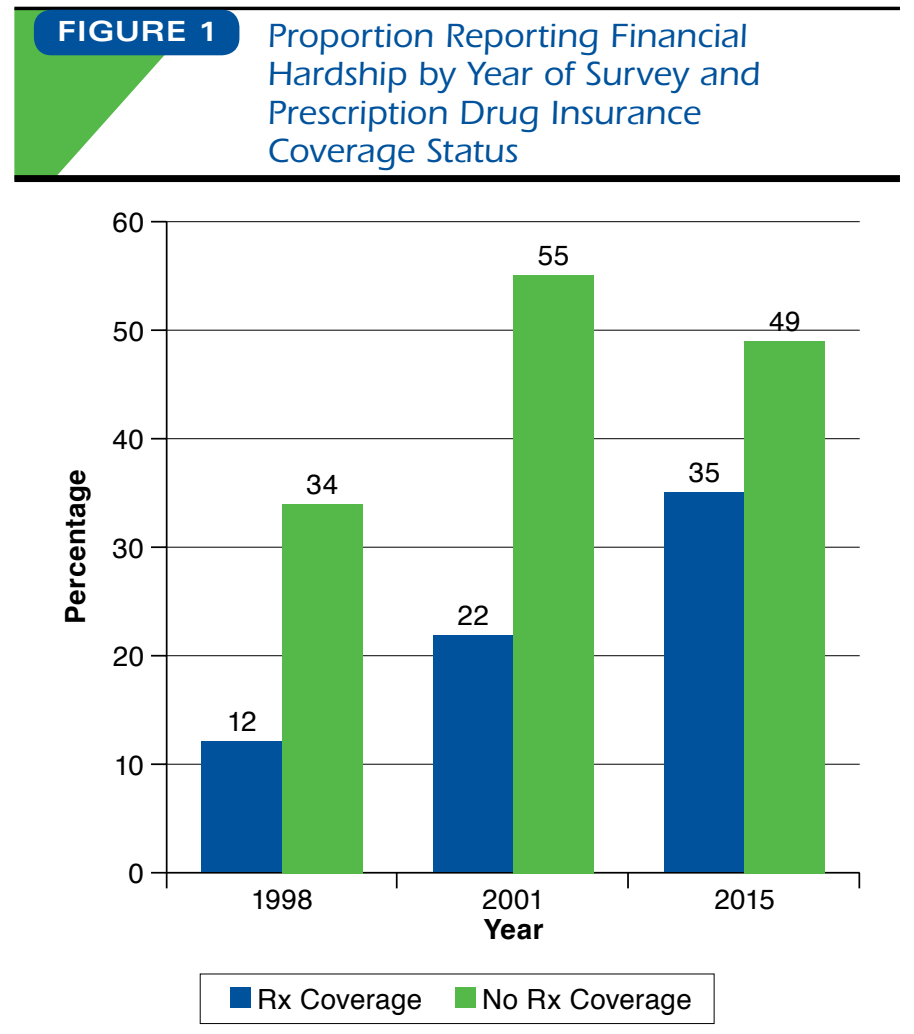

$R x=$ prescription

do not have prescription drug coverage). For each year, higher proportions of respondents without prescription drug coverage reported financial hardship compared with those with drug coverage ( $34 \%$ vs. $12 \%$ in $1998,55 \%$ vs. $22 \%$ in 2001 , $49 \%$ vs. $35 \%$ in 2015). It is noteworthy that respondents with prescription drug coverage reported financial hardship from 


\begin{tabular}{|c|c|c|c|c|}
\hline TA & \multicolumn{4}{|c|}{$\begin{array}{l}\text { Logistic Regression Results for } \\
\text { Likelihood of Experiencing Financial } \\
\text { Hardship Due to Prescription Drug } \\
\text { Expenditures (1998, 2001, and } \\
\text { 2015-Complete Sample }\end{array}$} \\
\hline Variable & $\begin{array}{c}\text { Wald } \\
\text { Statistic }\end{array}$ & $P$ Value & Odds Ratio & $95 \%$ CI \\
\hline \multicolumn{5}{|l|}{ Yearb } \\
\hline 2001 & 10.5 & $<0.001$ & 1.7 & $1.2-2.4$ \\
\hline 2015 & 14.2 & $<0.001$ & 1.6 & $1.2-2.0$ \\
\hline$\overline{\text { Currx }^{c}}$ & 26.0 & $<0.001$ & 1.04 & $1.02-1.06$ \\
\hline Incomed & 188.2 & $<0.001$ & 2.9 & $2.5-3.4$ \\
\hline Nocove & 137.8 & $<0.001$ & 3.0 & $2.5-3.6$ \\
\hline \multicolumn{5}{|c|}{$\begin{array}{l}a_{N}=4,587 ; \text { does not equal 4,693 due to missing values. } \\
\text { bYear: } 1998,2001 \text {, or 2015; reference group }=1998 \text {. } \\
{ }^{c} \text { Currx: Number of prescription medications taken daily (continuous variable). } \\
{ }^{d} \text { Income: } \geq \$ 15,000 \text { annual household income compared with }<\$ 15,000 ; \text { reference } \\
\text { group }=\geq \$ 15,000 \text {. In } 2015 \text {, the threshold was } \$ 20,000 \text {. } \\
{ }^{2} \text { Nocov: No prescription drug insurance coverage compared with have prescription } \\
\text { drug insurance coverage; reference group = have coverage. } \\
C I=\text { confidence interval. }\end{array}$} \\
\hline
\end{tabular}

purchasing medications in increasing proportions in 1998, 2001, and 2015 (12\%, 22\%, and 35\%, respectively).

Table 3 presents logistic regression results for the likelihood of experiencing financial hardship due to purchasing medications. The best-fitting model based on goodness-of-fit and parsimony of interpretation included the variables year, prescription drug use, income, and insurance coverage for prescription drugs. Controlling for year, prescription drug use, and income, logistic regression analysis showed that respondents without any prescription insurance coverage were about 3 times more likely to report financial hardship compared with those with coverage. When data from each survey year were analyzed in this manner, respondents without any prescription drug insurance coverage were 5 times more likely in both 1998 and 2001 and 2 times more likely in 2015 to report financial hardship compared with those with coverage. Logistic regression findings using the three 10\%-random-samples were stable and consistent with the overall findings presented in Table 3 (complete findings for the 10\%-random-samples are available from the corresponding author).

For the subset of respondents with prescription drug insurance coverage, the following variables were associated with financial hardship: year, number of prescriptions used daily, and income (Table 4). For this subset of respondents, 12\% reported financial hardship in 1998 compared with 22\% in 2001 and $35 \%$ in 2015 . Also, 30\% of these respondents with household incomes of $\$ 15,000$ or more reported financial hardship compared with $48 \%$ of respondents with household incomes of less

\begin{tabular}{|c|c|c|c|c|}
\hline TA & \multicolumn{4}{|c|}{$\begin{array}{l}\text { Logistic Regression Results for Likelihood } \\
\text { of Experiencing Financial Hardship Due } \\
\text { to Prescription Drug Expenditures (1998, } \\
\text { 2001, and 2015) for Respondents Who } \\
\text { Have Prescription Drug Insurance }\end{array}$} \\
\hline Variable & $\begin{array}{c}\text { Wald } \\
\text { Statistic }\end{array}$ & $P$ Value & Odds Ratio & $95 \%$ CI \\
\hline \multicolumn{5}{|l|}{ Yearb } \\
\hline 2001 & 6.4 & 0.010 & 2.0 & $1.2-3.3$ \\
\hline 2015 & 42.6 & $<0.001$ & 4.0 & $2.7-6.1$ \\
\hline Currx $^{c}$ & 44.6 & $<0.001$ & 1.06 & $1.04-1.08$ \\
\hline Income ${ }^{\mathrm{d}}$ & 75.2 & $<0.001$ & 2.2 & $1.8-2.6$ \\
\hline \multicolumn{5}{|c|}{$\begin{array}{l}{ }^{a} N=4,014 ; \text { does not equal } 4,045 \text { due to missing values. } \\
\text { bYear: } 1998 \text {, 2001, or } 2015 ; \text { reference group }=1998 \text {. } \\
\text { 'Currx: Number of prescription medications taken daily (continuous variable). } \\
\text { dincome: } \geq \$ 15,000 \text { annual household income compared with }<\$ 15,000 \text {; reference } \\
\text { group }=\geq \$ 15,000 \text {. In } 2015 \text {, the threshold was } \$ 20,000 \text {. } \\
\text { CI }=\text { confidence interval. }\end{array}$} \\
\hline
\end{tabular}

than $\$ 15,000$ per year (in 2015 , the threshold was $\$ 20,000$ ). For respondents with prescription drug coverage, those who reported financial hardship used an average of 4.9 prescriptions daily compared with respondents who did not report financial hardship who used 3.7 prescriptions daily $(P<0.001)$.

\section{Discussion}

After implementation of Medicare Part D and the ACA in 2010, the proportion of senior citizens without prescription drug coverage fell to $9 \%$ in 2015 . However, the proportion of senior citizens reporting financial hardship from purchasing medications rose to $36 \%$ in 2015 . In that year, $49 \%$ without prescription drug coverage reported financial hardship and 35\% with prescription drug coverage reported financial hardship.

The results also showed that lower-income seniors and higher users of prescription drugs continued being hit especially hard with the burden of drug costs. Insured persons were feeling the burden of drug costs as well, especially high users of prescription drugs. One explanation for the burden among insured persons is the increases in cost sharing experienced by insured persons. ${ }^{23-25}$ Copayments, coinsurance, deductibles, tiered formularies, and prior authorization tools have been used to reduce moral hazard (people with insurance coverage will use more-or more expensive-therapies than those without coverage) of prescription drug insurance by causing patients to realize the true cost of medications through their higher out-of-pocket expenses. However, increasing patient cost sharing also is associated with declines in medication adherence with resultant poorer health outcomes. ${ }^{26}$

Many insurers have long had tiered formularies that offer low cost sharing for generic drugs and higher cost sharing for 
brand-name drugs. However, the practice has expanded in recent years, with insurers adding "specialty tiers" that have very high cost sharing, often through coinsurance (a percentage of the total cost) instead of a copayment (a fixed dollar amount). ${ }^{27}$ Specialty-tier drugs may offer life-saving treatment to some of the sickest and most vulnerable patients. Yet the price tag for these treatments can be staggering, with patients owing thousands of dollars each month in coinsurance bills. ${ }^{27}$ Regardless of insurance status, drug costs continue to be a financial burden for many seniors, especially for high users of prescription drugs.

In light of these findings, there may be opportunities for pharmacists to continue to work with senior citizens to help them (a) select insurance that meets their needs, (b) use the insurance that maximizes value to them, and (c) find medication assistance when burdened. As pharmacists work with patients to improve medication use, they find several reasons for nonadherence, including the following:

- Directions are not understood

- Patient prefers to not take drug

- Patient forgets to take drug

- Drug product is too expensive

- Patient cannot swallow/administer drug

- Drug product is not available

An important part of comprehensive medication management relates to the financial hardship that can be experienced from purchasing medications.

\section{Limitations}

The results and our interpretation of them should be tempered by the limitations of the study. The results are based on respondents' self-reports, a method that raises a concern for insurance information as well as prescription drug use. ${ }^{28}$ A single question was used to measure financial hardship and was categorized as "yes" or "no." While serving as an indicator for financial hardship, this measure did not capture the intricacies of the construct.

Other limitations relate to sampling and selection bias. For example, nonresponders to health surveys may be older and in poorer health ${ }^{29}$ or, in terms of drug use, may use more medications. ${ }^{30,31}$ Thus, our findings may underestimate drug use for the senior citizen population.

Conversely, we found evidence in our study that individuals who did not use any medications decided not to participate because they thought that the survey did not apply to them. Also, the sampling frame and mailing addresses for the 1998 and 2001 surveys were obtained from a commercial mailing list company. Its database is updated constantly from public sources such as telephone directories and drivers license databases. However, by the time we mailed our surveys, it is likely that some members of our sample were deceased, physically or mentally no longer able to complete the survey, no longer at the address, or moved to a long-term-care or assisted living facility. We estimated that about half of nonresponders fit these categories based on results from individuals who provided reasons a sample member was not able to complete the whole survey (see Results). Based on feedback from sample members, it appears that the other half of the nonresponders had other reasons for not completing the survey such as (a) having no interest in completing surveys, (b) thinking that the survey did not apply to them because they did not take any medications, or (c) thinking that the survey did not apply to them because they received their medications through the military.

In 2015, an online survey approach used a commercial panel survey company and respondents may not have been representative of the whole U.S. senior citizen population. To overcome this limitation, response patterns were monitored and compared against established quotas and screening information for this particular study that included geographic location, age, and sex distributions. During data collection, sampling and survey invitations were adjusted in order to meet the desired respondent characteristics so that they matched the study population in terms of geographic location, age, and sex. Even so, sampling and selection bias are limitations that still need to be considered for this study.

\section{Conclusions}

The proportion of senior citizens without prescription coverage was 9\% in 2015, a decrease from 29\% in 2001 and 32\% in 1998. The proportion of senior citizens reporting financial hardship from medication purchases was 36\% in 2015, a rise from 31\% in 2001 and 19\% in 1998. For those without prescription drug coverage, 34\%, 55\%, and 49\% reported financial hardship in 1998, 2001, and 2015, respectively. For those with drug coverage, $12 \%, 22 \%$, and $35 \%$ reported financial hardship in 1998, 2001, and 2015, respectively.

After implementation of Medicare Part D and the ACA, the proportion of seniors without prescription drug coverage decreased. However, self-reported financial hardship from purchasing medications increased. Senior citizens with prescription drug insurance may be experiencing financial hardship from the ever-changing mix of drugs used by senior citizens and from the increasing out-of-pocket costs for insurance premiums, cost sharing, and full-cost obligation for some medications. 


\section{Authors}

ANTHONY W. OLSON, PharmD, and JON C. SCHOMMER, $\mathrm{PhD}$, University of Minnesota College of Pharmacy, Minneapolis, Minnesota. DAVID A. MOTT, PhD, University of WisconsinMadison School of Pharmacy, Madison, Wisconsin, and LAWRENCE M. BROWN, PhD, Chapman University School of Pharmacy, Irvine, California.

AUTHOR CORRESPONDENCE: Jon C. Schommer, PhD, University of Minnesota College of Pharmacy, 308 Harvard St., SE, Minneapolis, MN 55455. Tel.: 612.626.9915; Fax: 612.625.9931;

E-mail: schom010@tc.umn.edu.

\section{DISCLOSURES}

Funding was provided by the American Association of Colleges of Pharmacy New Investigator Program, the University of Minnesota Grant-in-Aid of Research Program, and the Peters Endowment for Pharmacy Practice Innovation. The authors have no conflicts of interest to declare.

Schommer, Mott, and Brown contributed to study design and collected the data, with assistance from Olson. Data interpretation was performed by Olson, Schommer, Mott, and Brown. The manuscript was written and revised by Olson, Schommer, Mott, and Brown.

\section{ACKNOWLEDGMENTS}

The authors gratefully acknowledge Richard Hansen, PhD, for his collaboration in translating foundational work in earlier studies to the findings presented in this article

\section{REFERENCES}

1. Mott, DA, Schommer, JC. Exploring prescription drug coverage and drug use for senior citizens. Ann Pharmacother. 2002;36:1704-11.

2. Sullivan SD, Gardner LB, Strandberg LT. The economics of outpatient prescription drug coverage for the elderly: implications for healthcare reform. Generations. 1994;18(2):55-60.

3. Families USA Foundation. Cost overdose: growth in drug spending for the elderly, 1992-2010. July 2000. Available at: http://www.policyarchive. org/handle/10207/6350. Accessed August 16, 2015.

4. Poisal JA, Chulis GS. Medicare beneficiaries and drug coverage. Health Aff (Millwood). 2000;19(2):248-56

5. Safran DG, Neuman P, Schoen C, et al. Prescription drug coverage and seniors: how well are states closing the gap? Health Aff (Millwood). 2002; Suppl Web Exclusives:W253-68.

6. Department of Health and Human Services. Report to the president: prescription drug coverage, spending, utilization, and prices. April 1, 2000. Available at: https://aspe.hhs.gov/report/report-president-prescription-drugcoverage-spending-utilization-and-prices. Accessed August 13, 2016.

7. Davis M, Poisal J, Chulis GA, Zarabozo C, Cooper B. Prescription drug coverage, utilization, and spending among Medicare beneficiaries. Health Aff (Millwood). 1999;18(1):231-43.

8. Cox ER, Henderson RR. Prescription use behavior among Medicare beneficiaries with capped prescription benefits. J Manag Care Pharm. 2002;8(5):360-64. Available at: http://www.jmcp.org/doi/10.18553/ jmcp.2002.8.5.360.
9. Majeski T. Seniors get Canada-sized discount on prescriptions. Pioneer Press. January 22, 2003. Available at: https://www.highbeam.com/ doc/1Gl-119240565.html. Accessed August 19, 2016.

10. Stuart B, Grana J. Ability to pay and the decision to medicate. Med Care. 1998;36(2):202-11.

11. Stuart B, Grana J. Are prescribed and over-the-counter medicines economic substitutes? A study of the effects of health insurance on medicine choices by the elderly. Med Care. 1995;33(5):487-501.

12. Kaufman DW, Kelly JP, Rosenberg L, Anderson TE, Mitchell AA. Recent patterns of medication use in the ambulatory adult population of the United States. JAMA. 2002;287(3):337-44.

13. Kaiser Family Foundation. Summary of the Affordable Care Act. April 25, 2013. Available at: http://kff.org/health-reform/fact-sheet/summary-ofthe-affordable-care-act/. Accessed August 19, 2016.

14. Government Accounting Office. State pharmacy programs: assistance designed to target coverage and stretch budgets. September 6, 2000. HEHS00-162. Available at: http://www.gao.gov/assets/240/230600.pdf. Accessed August 13, 2016.

15. Schommer, JC, Mott, DA, Hansen, RA, Cline, RR. Selected characteristics of senior citizens' prescription drug payment and procurement in 1998 and 2001. J Manag Care Pharm. 2003;9(5):408-15. Available at: http://www. jmcp.org/doi/abs/10.18553/jmcp.2003.9.5.408.

16. Jacobson G, Anderson G. Medicare Part D: ongoing challenges for doctors and patients. Annu Rev Med. 2010,61:469-76.

17. Zhang Y, Donohue JM, Newhouse JP, Lave JR. The effects of the coverage gap on drug spending: a closer look at Medicare Part D. Health Aff (Millwood). 2009;28(2):w317-25.

18. Hsu J, Price M, Huang J, et al. Unintended consequences of caps on Medicare drug benefits. N Engl J Med. 2006; 354(22):2349-59.

19. Kaplan L. A primer on Medicare and changes resulting from the Patient Protection and Affordable Care Act. Nurse Pract. 2013; 38(2):8-9.

20. Centers for Medicare \& Medicaid Services. Costs in the coverage gap. 2015. Available at: https://www.medicare.gov/part-d/costs/coverage-gap/partd-coverage-gap.html. Accessed August 13, 2016.

21. Department of Health and Human Services. Since 2010, 9.4 million people with Medicare have saved over $\$ 15$ billion on prescription drugs. News release. February 24, 2015. Available at: http://www.hhs.gov/about/ news/2015/02/24/since-2010-9-point-4-million-people-with-medicare-havesaved-over-15-billion-on-prescription-drugs.html\#. Accessed August 13, 2016.

22. Dillman DA. Mail and Telephone Surveys: The Total Design Method. New York: Wiley Publishing; 1978.

23. Q1Medicare.com. Q1 Group LLC. Medicare Part D prescription drug plan \& Medicare Advantage plan information. Available at: https://www. qlmedicare.com. Accessed August 13, 2016.

24. Centers for Medicare \& Medicaid Services. Medicare general information, eligibility, and entitlement. Chapter 3-Deductibles, coinsurance amounts, and payment limitations. November 25, 2015. Available at: https:// www.cms.gov/Regulations-and-Guidance/Guidance/Manuals/downloads/ gel01c03.pdf. Accessed August 13, 2016.

25. Paez KA, Zhao L, Hwang W. Rising out-of-pocket spending for chronic conditions: a ten-year trend. Health Aff (Millwood). 2009;28(1):15-25.

26. Eaddy MT, Cook CL, O'Day K, Burch SP, Cantrell CR. How patient cost-sharing trends affect adherence and outcomes: a literature review. P.T. 2012;37(1):45-55. 
27. Corlette S, Williams A, Giovannelli J. State efforts to reduce consumers' cost-sharing for prescription drugs. The Commonwealth Fund blog. November 16, 2015. Available at: http://www.commonwealthfund.org/publications/blog/2015/nov/state-efforts-to-reduce-consumers-cost-sharing-forprescription-drugs. Accessed August 13, 2016.

28. Steinberg EP, Gutierrez B, Momani A, Boscarino JA, Neuman P, Deverka P. Beyond survey data: a claims-based analysis of drug use and spending by the elderly. Health Aff (Millwood). 2000;19(2):198-211.
29. Osler M, Schroll M. Differences between participants and non-participants in a population study on nutrition and health in the elderly. Eur J Clin Nutr. 1992;46:289.

30. Berk M, Schur C, Mohr P. Using survey data to estimate prescription drug costs. Health Aff (Millwood). 1990;9:146-57.

31. Grotzinger KM, Stuart BC, Ahern F. Assessment and control of non-response bias in a survey of medicine use by the elderly. Med Care. 1994;32(10):989-1003. 